\title{
EDITORIAL
}

\section{Asthma and atopy: has peak prevalence been reached?}

\author{
D. Nowak*, C. Suppli Ulrik", E. von Mutius"
}

Numerous studies have been published concerning the changing epidemiology of asthma and atopy, and studies from "western countries" have consistently shown a dramatic increase in prevalence over the last two to three decades. However, in this issue of the European Respiratory Journal, BRAUN-FAHRLÄNDER et al. [1] report interesting new evidence concerning the prevalence rates of asthma and atopy in a group of Swiss teenagers. Their repeated cross-sectional survey of 14-yr-old children shows that the prevalence of asthma and current asthmatic symptoms remained constant between 1992 and 2000. Likewise, no further increase was found in hay fever rates and allergic sensitisation during the same period. Asthma and hay fever diagnoses were based on written and/or video questionnaires, and sensitisation was determined by multiscreen SX1 tests (and afterwards confirmed by measurements of specific immunoglobulin E levels). Therefore, although additional years of data collection are necessary to confirm a change in trend, their observations clearly suggest that the increase in asthma and atopy may have come to an end, at least in some societies.

These data are in line with some recently published studies showing a plateau in the prevalence of both childhood asthma [2-4], including asthma attack prevalence in the past 12 months and hospitalisations for acute asthma, and adult asthma $[5,6]$. In contrast, other observations suggest that the asthma prevalence in both children [7] and adults [8,9] is still on the rise.

One strength of the Swiss investigation is certainly the inclusion of objective parameters for the assessment of atopy. Clearly, no change in the prevalence of inhalant sensitisation was seen over the study period. On a population level the strength of association between atopy and asthma may vary widely [10]. This discrepancy seems particularly relevant in developing countries, where even inverse relationships between mite sensitisation and asthma were found. These effects may, in part, be attributable to endemic parasitic infections in developing areas [11]. In western countries, a strong association between atopic sensitisation and asthma is seen particularly among adolescents, lending support to the Swiss findings of a plateau.

If these recent data are accepted as indicating at least some levelling-off in asthma and atopy, and more data demonstrating the same findings are also expected in the next years, then what could be a plausible explanation? As changes in the prevalence of asthma and atopy have been much faster than the genetic constitution of any population can possibly shift, a genetic basis is unlikely. The most likely explanation is,

\footnotetext{
*Institut und Poliklinik für Arbeits- und Umweltmedizin, Klinikum der Universität München, and "Haunersches Kinderspital der Universität München, Munich, Germany. ${ }^{\#}$ Dept of Respiratory Diseases, Hvidovre Hospital, Hvidovre, Denmark.

Correspondence: D. Nowak, Institut und Poliklinik für Arbeits- und Umweltmedizin, Klinikum der Universität München, Ziemssenstr. 1, D-80336 München, München, Germany. Fax: 49 8951604445. E-mail: dennis.nowak@arbeits.med.uni-muenchen.de
}

therefore, not surprisingly, changes in environmental exposures. However, changes in nutrition and obesity, exposure to air pollution, tobacco smoke, viral infections, exposure to endotoxin, pets, or any other known or suspected risk or protective factor cannot explain this sort of trend in the way of a simple exposure-response relationship. Likewise, none of the potential risk factors in the study of BRAUN-FAHRLÄNDER et al. [1] explained their findings. In turn, one might argue that during this period, the prevalence of none of the potential risk factors has increased substantially over time to achieve a change in the prevalence of these conditions on a population level.

Unravelling a potential cohort effect might yield clues to those factors contributing to the increase, and perhaps levelling off, of asthmatic and allergic diseases. The decrease of allergic sensitisation with increasing age might not only reflect the natural course of disease, but might well be due to an increase amongst subjects born around and after the $1960 \mathrm{~s}$ $[12,13]$.

As it can hardly be stated that the process of "westernisation" has been levelling off within the last one or two decades, it appears more likely that the "ceiling level" or "saturation" is being approached, i.e. the proportion of the population that has the potential of acquiring asthma and/or getting sensitised may be reached, or in other words that the maximum effect of changing environmental exposure in susceptible individuals may be seen. Even in well-defined high-exposure settings in occupational respiratory and allergic disease, the prevalence of sensitisation never exceeds, say, $50 \%$ of the exposed workforce. Conversely, about half of the population may be genetically resistant to any sort of sensitisation whatever the environmental conditions may be. Promising studies on genetic-environmental interaction will hopefully shed more light on the mechanisms of resistance or susceptibility.

So, what is the type of studies that will help us to understand the consistencies and inconsistencies in the changing time trends of asthma, rhinitis and atopy? First, it is studies in which asthma, like atopy, is also diagnosed by an "objective" marker. In their critical (but rarely quoted) appraisal, WIERINGA et al. [14] found only nine articles on time trends of asthma and atopy in which objective measures of airway responsiveness and atopy were used twice in the whole population under study. Three of these reported nonsignificant changes. The other six articles found a significant increase in at least one objective measurement and of these only three reported a consistent significant increase. Therefore, studies emerging from the European Community Respiratory Health Survey II are clearly at the top of scale of scientific interest.

Secondly, studies with discrepancies between asthma on the one hand and atopic sensitisation on the other hand may shed more light, such as reports from Gambia [15] with $35.3 \%$ atopy and $3.6 \%$ asthma or China [16] with $49.0 \%$ atopy and $1.9 \%$ asthma. The influence of environmental factors in these mainly developing countries on the development of both outcomes will be highly interesting to study. 
Thirdly, areas with rapidly changing environments, as has occurred in Eastern Germany, provide fascinating large-scale intervention data. For example, 5 yrs after German reunification, atopy but not bronchial hyperresponsiveness rose in eastern parts of Germany [17, 18]. Urbanisation studies in rural populations with low prevalences of both asthma and atopy among farmers' children [19] and adult farmers [20] might prove interesting as well.

Fourthly, migrant studies, which strongly point to the importance of environmental rather than genetic factors being responsible for the manifestation of asthma and atopic diseases [21, 22], might provide clues to differential influences on various manifestations under very rapidly changing environmental conditions. Studies fulfilling the "Wieringa criteria" are clearly warranted in this field.

\section{References}

1. Braun-Fahrländer C, Gassner M, Grize L, et al. No further increase in asthma, hay fever and atopic sensitisation in adolescents living in Switzerland. Eur Respir J 2004; 23: 407413.

2. Akinbami LJ, Schoendorf KC. Trends in childhood asthma: prevalence, health care utilization, and mortality. Pediatrics 2002; 110: 315-322.

3. Ronchetti R, Villa MP, Barreto M, et al. Is the increase in childhood asthma coming to an end? Finding from three surveys of schoolchildren in Rome, Italy. Eur Respir J 2001; 17: 881-886.

4. Kalyoncu AF, Selcuk ZT, Enünlü T, et al. Prevalence of asthma and allergic diseases in primary school children in Ankara, Turkey: two cross-sectional studies, five years apart. Pediatr Allergy Immunol 1999; 10: 261-265.

5. Fleming DM, Sunderland R, Cross KW, Ross AM. Declining incidence of episodes of asthma: a study of trends in new episodes presenting to general practitioners in the period 1989-98. Thorax 2000; 55: 657-661.

6. Verlato $\mathrm{G}$, Corsico A, Villani S, et al. Is the prevalence of adult asthma and allergic rhinitis still increasing? Results from an Italian study. J Allergy Clin Immunol 2003; 111: 1232-1238.

7. Maziak W, Behrens T, Brasky TM, et al. Are asthma and allergies in children and adolescents increasing? Results from ISAAC phase I and phase III surveys in Münster, Germany. Allergy 2003; 58: 572-579.

8. Downs SH, Marks GB, Sporik R, Belosouva EG, Car NG, Peart JK. Continued increase in the prevalence of asthma and atopy. Arch Dis Child 2001; 84: 20-23.
9. Brogger J, Bakke P, Eide GE, Johansen B, Andersen A, Gulsvik A. Long-term changes in adult asthma prevalence. Eur Respir J 2003; 21: 468-472.

10. Pearce N, Pekkanen J, Beasley R. How much asthma is really attributable to atopy? Thorax 1999; 54: 268-272.

11. Scrivener S, Yemaneberhan $\mathrm{H}$, Zebenigus $\mathrm{M}$, et al. Independent effects of intestinal parasite infection and domestic allergen exposure on risk of wheeze in Ethiopia: a nested case-control study. Lancet 2001; 358: 1493-1499.

12. Heinrich J, Nowak D, Wassmer G, Jörres R, et al. Agedependent differences in the prevalence of allergic rhinitis and atopic sensitization between an eastern and a western German city. Allergy 1998; 53: 89-93.

13. Linneberg A, Nielsen NH, Madsen F, Frolund L, Dirksen A, Jorgensen $\mathrm{T}$. Is the increase in allergic respiratory disease caused by a cohort effect? Clin Exp Allergy 2002; 32: 17021705 .

14. Wieringa MH, Vermeire PA, Brunekreef B, Weyler JJ. Increased occurrence of asthma and allergy: critical appraisal of studies using allergic sensitization, bronchial hyperresponsiveness and lung function measurements. Clin Exp Allergy 2001; 31: 1553-1563.

15. Walraven GEL, Nyan OA, van der Sande MA, et al. Asthma, smoking and chronic cough in rural and urban adult communities in the Gambia. Clin Exp Allergy 2001; 31: $1679-1685$.

16. Leung R, Ho P. Asthma, allergy and atopy in three southeast Asian populations. Thorax 1994; 49: 1205-1210.

17. Von Mutius E, Weiland SK, Fritzsch C, Duhme H, Keil U. Increasing prevalence of hay fever and atopy among children in Leipzig, East Germany. Lancet 1998; 351: 862866.

18. Weiland SK, von Mutius E, Hirsch T, et al. Prevalence of respiratory and atopic disorders among children in the East and West of Germany five years after unification. Eur Respir $J$ 1999; 14: 862-870.

19. Braun-Fahrländer Ch, Riedler J, Herz U, et al. Environmental exposure to endotoxin and its relation to asthma in school-age children. N Engl J Med 2002; 347: 869-877.

20. Radon K, Danuser B, Iversen M, et al. Respiratory symptoms in European animal farmers. Eur Respir J 2001; 17: 747-754

21. Grüber C, Illi S, Plieth A, Sommerfeld C, Wahn U. Cultural adaptation is associated with atopy and wheezing among children of Turkish origin living in Germany. Clin Exp Allergy 2002; 32: 526-531.

22. Tedeschi A, Barcella M, Dal Bo GA, Miadonna A. Onset of allergy and asthma symptoms in extra-European immigrants to Milan, Italy: possible role of environmental factors. Clin Exp Allergy 2003; 33: 449-454. 